\title{
Selective induction of apoptosis in human gastric cancer cells by Lactobacillus kefiri (PFT), a novel kefir product
}

\author{
MAMDOOH GHONEUM and NOURAN FELO \\ Department of Otolaryngology, Charles R. Drew University of Medicine and Science, Los Angeles, CA 90059, USA
}

Received May 21, 2015; Accepted July 10, 2015

DOI: 10.3892/or.2015.4180

\begin{abstract}
The present study was undertaken to evaluate the effect of Lactobacillus kefiri (PFT), a novel kefir product, on apoptosis of gastric cancer cells (AGS), breast cancer cells (4T1), and human peripheral blood mononuclear cells (PBMCs). Cells were cultured with PFT and apoptosis was determined by flow cytometry using 7-AAD dye and cytospin preparation. Mitochondrial dysfunction and expression of $\mathrm{Bcl} 2$ were monitored by flow cytometry. Results showed that PFT induced apoptosis in AGS gastric cancer cells in a dose-dependent manner. Apoptosis was detected at a concentration of $0.3 \mathrm{mg} / \mathrm{ml}(20.8 \%)$, increased to $25.8 \%$ at $0.6 \mathrm{mg} / \mathrm{ml}$, $37 \%$ at $1.2 \mathrm{mg} / \mathrm{ml}, 53.1 \%$ at $2.5 \mathrm{mg} / \mathrm{ml}$, and peaked at $66.3 \%$ at $5.0 \mathrm{mg} / \mathrm{ml}$. Apoptosis is associated with the decreased polarization of mitochondrial membrane potential (MMP) and decreased Bcl2 expression. PFT-treated AGS cells manifested membrane blebbing, nuclear condensation, and fragmentation as identified in cytospin cytocentrifuge Giemsa stained preparations. On the other hand, flow cytometry analysis showed that PFT did not induce apoptosis in 4T1 breast cancer cells nor in PBMCs. These results suggest that PFT is safe for white blood cells and selectively induces apoptotic effects in gastric cancer cells. Hence, it may have potential as a therapeutic agent for the treatment of gastric cancers.
\end{abstract}

\section{Introduction}

Globally, stomach cancer is the fifth most common type of cancer and the third leading cause of cancer deaths, making up $7 \%$ of cases and $9 \%$ of deaths (1). In 2012, 950,000 people contracted stomach cancer worldwide, leading to 723,000 deaths (1). In 2014, the United States recorded an estimated 22,220 new cases and 10,990 deaths from stomach cancer (2). Outcomes are often poor with a $<10 \% 5$-year survival rate globally, and a $28 \%$ 5-year survival rate in the

Correspondence to: Dr Mamdooh Ghoneum, Department of Otolaryngology, Charles R. Drew University of Medicine and Science, 1621 E. 120th Street, Los Angeles, CA 90059, USA

E-mail:mghoneum@ucla.edu

Key words: Lactobacillus kefiri, gastric cancer, apoptosis, mitochondrial polarization
United States (3). Gastric cancer is a multifactorial disease. The most common cause is infection by the bacteria Helicobacter pylori, which is responsible for $65-80 \%$ of gastric cancers (4), though other factors such as genetics, smoking, and diet (especially eating pickled vegetables) have also been shown to play an important role in the development of gastric cancer. Surgery, chemotherapy, radiation therapy, and targeted therapy are commonly used to treat this disease (5), and if treated late, palliative care may also be advised (4).

Chemotherapy aims to initiate apoptosis in gastric cancer cells $(6,7)$; however, these drugs can be toxic. Therefore, recent studies have made an effort to investigate alternative treatments that have fewer and less potent side effects. Lactic acid bacteria (LAB) may represent a useful approach for the treatment of cancer. LAB are present in many foods such as yogurt and have been shown to elicit antitumor effects. Probiotics have been shown to act preventatively in in vitro studies and during carcinogenesis in studies on animals bearing tumors. For example, multiple studies show various LAB strains exert inhibitory effects on the growth of different types of tumors in rodents (8-11).

Earlier studies also reveal that different strains of LAB have anti-proliferative effects against human cancer cell lines. For example, Lactococcus lactis ssp. lactis (L.lac CF) induces apoptosis on the human colon cancer cell line SNUC2A (12), L. casei rhamnosus induces apoptosis in the human monocytic leukemia cell line THP-1 (13), and L. reuteri enhances tumor necrosis factor (TNF)-induced apoptosis in human chronic myeloid leukemia-derived cells (14). Furthermore, probiotic consumption might be associated with reducing the incidence of colon tumors, as shown in epidemiological studies (15). This data suggests that fermented milk products and/or the fermentative bacteria themselves may have chemoprotective effects without the toxic side effects of conventional therapeutic drugs.

Probiotics Fermentation Technology (PFT), a kefir grain product, is a natural mixture composed primarily of Lactobacillus kefiri P-IF, a specific strain of L. kefiri with unique growth characteristics. Our recent studies have demonstrated the ability of PFT to induce apoptosis on human MDR myeloid leukemia (HL60/AR) cells in vitro (16). The present study was designed to examine the possible apoptotic effect of PFT against other types of cancer, specifically the human gastric cancer AGS cells, and murine breast cancer 4T1 cells, in vitro. It was of interest to note that PFT selec- 
tively exerts apoptotic effects on AGS cells, but not on 4T1 cells. Furthermore, PFT showed no apoptotic effect on human PBMCs. The mechanism underlying the effect of PFT was examined.

\section{Materials and methods}

Tumor cell lines. Two cancer cell lines were used in the present study, namely: AGS, a human gastric adenocarcinoma cell line, and 4T1, a murine breast cancer cell line. The cells were purchased from American Tissue and Culture Collection (ATCC) (Manassas, VA, USA). AGS tumor cells were maintained in Dulbecco's modified Eagle's medium (DMEM) (Invitrogen Corp., Carlsbad, CA, USA) supplemented with 10\% fetal bovine serum (FBS) and $2 \mathrm{mM}$ glutamine, and $100 \mu \mathrm{g} / \mathrm{ml}$ streptomycin and penicillin. 4T1 tumor cells were maintained in RPMI-1614 (Invitrogen Corp.) supplemented with 10\% FBS and $2 \mathrm{mM}$ glutamine, and $100 \mu \mathrm{g} / \mathrm{ml}$ streptomycin and penicillin. Cells were routinely maintained in log phase in a humidified incubator at $37^{\circ} \mathrm{C}$ with $5 \% \mathrm{CO}_{2}$.

Probiotics Fermentation Technology (PFT) kefir grain product. PFT is a mixture that consists mainly $(\sim 90 \%)$ of a freeze-dried form of heat-killed $L$. kefiri P-IF. In addition, PFT contains $\sim 2-3 \%$ each, of one bacterial strain L. kefiri $\mathrm{P}-\mathrm{B} 1$, as well as the yeast strains Kazachstania turicensis, Kazachstania unispora and Kluyveromyces marxianus. $\mathrm{P}-\mathrm{IF}$ is a specific strain of LAB that has a unique DNA sequence, and PET scans show a $99.6 \%$ homology with regular kefiries. Its characteristics were recently reported (16). PFT was provided by Paitos Co., Ltd., Yokohama, Kanagawa, Japan.

PFT induces apoptosis on cancer cells - flow cytometry study. 7-Aminoactinomycin D (7-AAD staining) was used to detect cancer cell viability. AGS cells were cultured in the presence or absence of PFT at different concentrations $(0.0,0.3,0.6$, $1.2,2.5$ and $5 \mathrm{mg} / \mathrm{ml}$ ) for 3 days and the percentage of dead cancer cells was examined by 7-AAD (BD Biosciences, San Diego, CA, USA) technique using a FACSCalibur (BectonDickinson, San Jose, CA, USA). Briefly, the cells were stained for $30 \mathrm{~min}$ at room temperature in the dark with $5 \mu \mathrm{l}$ of 7-AAD and analyzed by FACSCalibur.

PFT induces apoptosis on AGS cancer cells - morphological analysis. Cytospin preparations stained with Giemsa allowed us to examine PFT-induced apoptotic cancer cells. Several morphological characteristics have been used to identify apoptotic cells including cell swelling, membrane blebbing and chromatin condensation (17).

Growth of monolayer cancer cells in 6-well plates. We followed our earlier model assay system (18) to examine apoptosis of monolayer AGS cells post-culturing with PFT. Apoptosis in adherent and non-adherent AGS cells was monitored. Cancer cells were allowed to grow in 6-well plates $(25 \times 36 \mathrm{~mm}$ each, CellStar, Greiner Bio-One, Monroe, NC, USA). A cover glass was placed at the bottom of each well. AGS cells $/ \mathrm{ml}$ $\left(1 \times 10^{5} / 2 \mathrm{ml}\right)$ were pipetted into each well, allowed to adhere and reach $50-60 \%$ confluency. PFT $(5.0 \mathrm{mg} / \mathrm{ml})$ was added to each well and incubated at $37^{\circ} \mathrm{C}$ and $5 \% \mathrm{CO}_{2}$. At 0.5 and
$24 \mathrm{~h}$, both non-adherent and adherent cells were examined as follows:

a) Non-adherent cells. The supernatant containing nonadherent tumor cells ( $1 \mathrm{ml}$ ) was mixed with $100 \mu \mathrm{l}$ of trypan blue to make cytospin preparations (Shandon Southern Instruments, Sewickly, PA, USA). Preparations were fixed in $100 \%$ methanol, air-dried, stained with $4 \%$ Giemsa for $20 \mathrm{~min}$ (Sigma-Aldrich Corp., St. Louis, MO, USA) and examined using oil immersion and a light microscope fitted with a 100x objective (Leica DMLB microscope and Leica DFC310FX digital color camera, Germany). The supernatant was also used to count the number of apoptotic non-adherent cancer cells using a hemocytometer.

b) Adherent cells. Cover glasses containing adherent cells were carefully removed, air-dried, mounted on slides, fixed in methanol and stained with Giemsa as above. The cells were analyzed morphologically using oil immersion and a light microscope fitted with a 100x objective (Leica microscope). In addition, the preparations were used to calculate the percentage of apoptotic adherent cancer cells. The number of adherent cells was calculated from observations at 5 different sites on the cover slip, each containing $\sim 80$ cells. The percentage of apoptotic cells was determined by dividing the number of apoptotic cells by the total number of cells calculated.

\section{Mechanism underlying PFT effect}

a) Expression of $\mathrm{Bcl}-2$. For detection of Bcl-2, cells were first fixed and permeabilized with ice-cold $70 \%$ methanol. Cells were then stained with FITC-labeled anti-Bcl-2 or isotype control (Dako Corp., Carpinteria, CA, USA), washed and analyzed by FACSCalibur. The percentage of cells expressing Bcl-2 and mean fluorescent intensity (an indicator of density of the molecules/cell) was determined.

b) Detection of mitochondrial membrane potential (MMP). Variations of the mitochondrial transmembrane potential $\Delta \Psi_{m}$ during apoptosis were studied using tetramethylrhodamine ethylester (TMRE, Molecular Probes, Eugene, OR, USA). After treatment with PFT for 3 days, cancer cells $\left(5 \times 10^{5}\right.$ cells $\left./ \mathrm{ml}\right)$ were incubated with $50 \mathrm{nM}$ TMRE for $30 \mathrm{~min}$ at $37^{\circ} \mathrm{C}$, washed with PBS, and analyzed with FACSCalibur. The side scatters were used to gate and exclude cellular debris using a FACSCalibur. The cells were excited at $488 \mathrm{~nm}$ and the emission was collected on the FL2 channel. Five thousand cells were analyzed. The data were acquired and analyzed using CellQuest software (Becton-Dickinson). A decrease in red fluorescence indicates loss of membrane potential $\Delta \Psi_{m}$.

Effect of PFT with human peripheral blood mononuclear cells (PBMCs). PBMCs from three normal healthy donors [approved by the Institutional Review Board (IRB), Charles Drew University, Los Angeles, CA, USA] were separated over Ficoll-hypaque density gradient centrifugation. Cells $\left(1 \times 10^{6} / \mathrm{ml}\right)$ were cultured with or without PFT $(5.0 \mathrm{mg} / \mathrm{ml})$ for 3 days. Cells were examined for the percentage of apoptosis.

Statistical analysis. Using the Student's t-test, we tested the significance of difference in the percent changes of apoptotic 


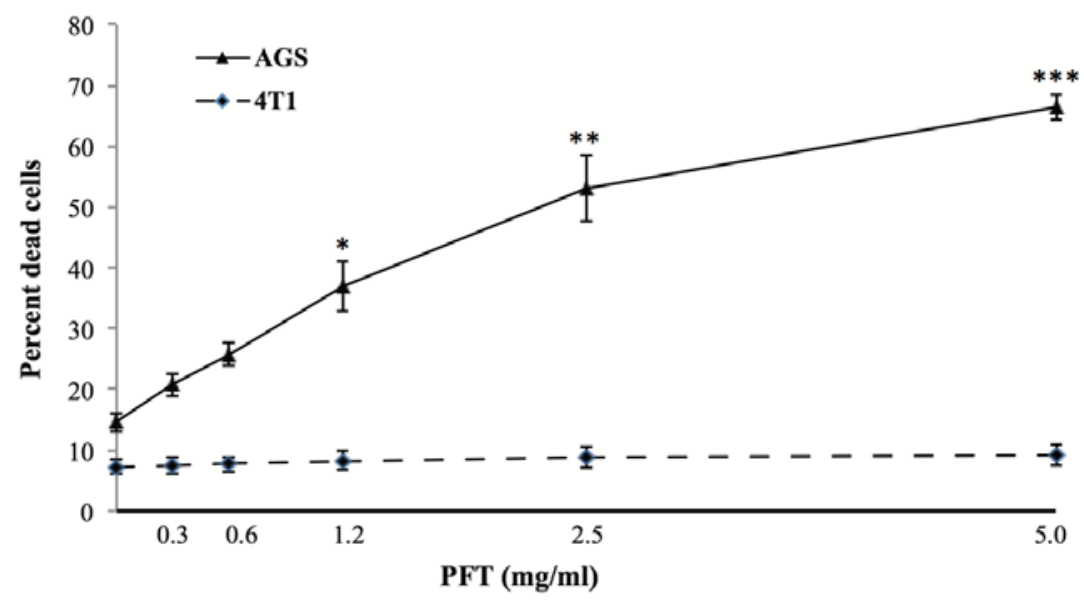

Figure 1. Effect of PFT on the percentage of apoptotic cancer cells by flow cytometry. AGS and 4T1 cells $\left(1 \times 10^{5}\right)$ were cultured with PFT at concentrations of $0-5 \mathrm{mg} / \mathrm{ml}$ for 3 days. Cell death was determined by flow cytometry using 7-AAD dye. Data represent the mean $\pm \mathrm{SE}$ of 4 experiments at each concentration. ${ }^{*} \mathrm{p}<0.05,{ }^{* *} \mathrm{p}<0.001,{ }^{* * *} \mathrm{p}<0.0001$.

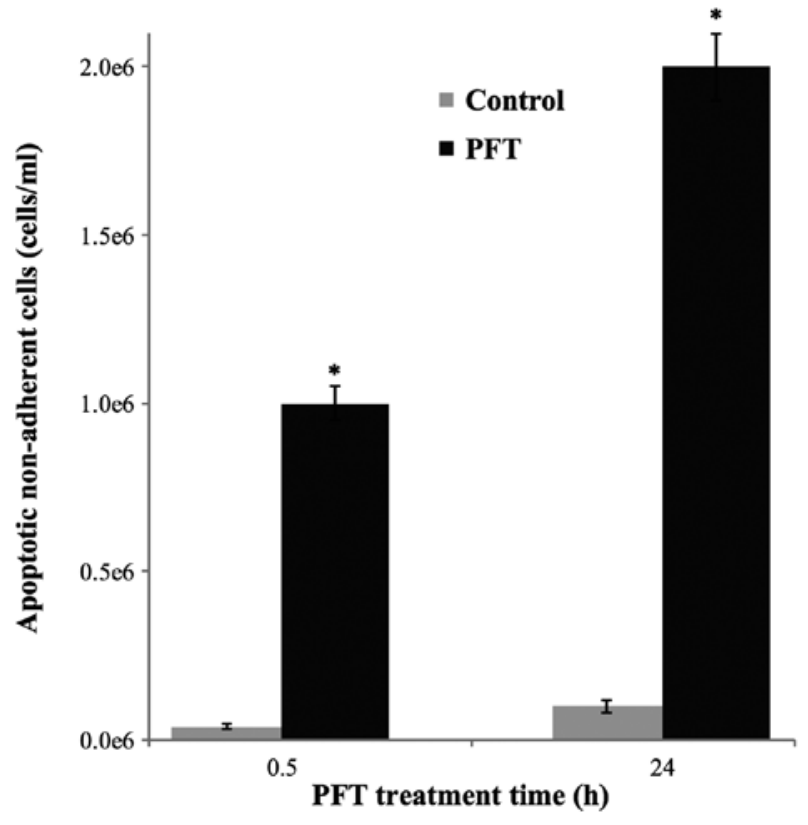

Figure 2. Number of apoptotic non-adherent AGS cells post-culture with PFT $(5.0 \mathrm{mg} / \mathrm{ml})$. Tumor cells were cultured in the absence (grey) or presence of PFT (black). The number of non-adherent apoptotic tumor cells was determined at 0.5 and $24 \mathrm{~h}$ using a hemocytometer. Data represent the mean $\pm \mathrm{SD}$ of 3 experiments. " $p<0.001$ as compared to control untreated cells.

cancer cells and PBMCs post-culture with PFT as compared to control untreated cells alone. The level of significance was set at $\mathrm{p}<0.05$.

\section{Results}

Percent apoptotic cancer cells by flow cytometry. AGS and 4T1 cells were cultured with PFT at concentrations $0-5 \mathrm{mg} / \mathrm{ml}$ for 3 days, and the percent apoptotic cancer cells was determined by flow cytometry using 7-AAD dye. Fig. 1 shows that PFT induced apoptosis in AGS cancer cells in a dosedependent manner. An increase in the percentage of apoptotic
AGS cells was detected at lower concentrations of PFT $(0.3$ and $0.6 \mathrm{mg} / \mathrm{ml}$ ). The percent apoptotic cells became significant at a concentration of $1.2 \mathrm{mg} / \mathrm{ml}(37.0 \%, \mathrm{p}<0.05)$, with a further increase at $2.5 \mathrm{mg} / \mathrm{ml}(53.1 \%, \mathrm{p}<0.001)$ and maximized at $5 \mathrm{mg} / \mathrm{ml}(66.3 \%, \mathrm{p}<0.0001)$. Notably, PFT does not induce apoptosis in $4 \mathrm{~T} 1$ cancer cells $\leq 5 \mathrm{mg} / \mathrm{ml}$.

Morphological analysis of apoptotic cancer cells by Giemsa staining. Cancer cells were cultured with PFT $(5.0 \mathrm{mg} / \mathrm{ml})$ and the percentage/number of apoptotic cells among the nonadherent and monolayer adherent cancer cells was examined.

a) Non-adherent apoptotic AGS cancer cells. AGS cancer cells were cultured with PFT for 0.5 and $24 \mathrm{~h}$ and the supernatant containing non-adherent cells was collected and the number of apoptotic cancer cells was examined by trypan blue staining and hemocytometer. Data depicted in Fig. 2 show a significant increased level of apoptotic non-adherent cells at $0.5 \mathrm{~h}$. The number of apoptotic cancer cells was further increased at $24 \mathrm{~h}$, showing a 2-fold increase in comparison to the $0.5 \mathrm{~h}$.

\section{b) Monolayer adherent apoptotic AGS cells.}

i) Morphological characteristics. We were able to identify the apoptotic AGS cancer cells in Giemsa-stained monolayer AGS cells grown on cover glass post-culture with PFT $(5.0 \mathrm{mg} / \mathrm{ml})$ for $24 \mathrm{~h}$. PFT induces the common morphological characteristics of apoptosis including cell swelling, membrane blebbing, and chromatin condensation. Fig. 3A shows non-apoptotic adherent AGS cells. Note the absence of chromatin condensation and membrane blebbing. Cancer cells undergoing apoptosis begin with chromatin condensation, in which the nucleus shrinks to about half the size of the cell (Fig. 3B). This is followed by membrane blebbing (Fig. 3C) and nuclear fragmentation (Fig. 3D). Finally, nuclear fragments become encased in membrane vesicles (Fig. 3E), and subsequently these vesicles become detached from the cell. Note that spherical and ovular vesicles are completely detached and autonomous from the apoptotic cell (Fig. 3F). On the other hand, we observed absence of chromatin condensation and 


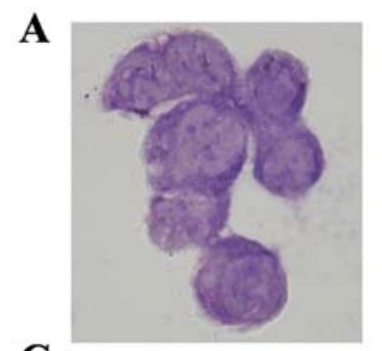

C
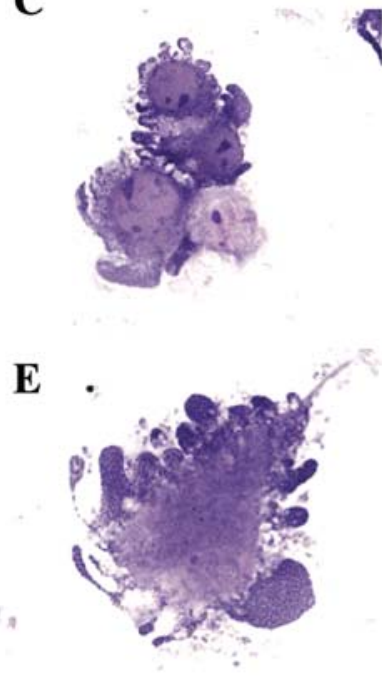

B

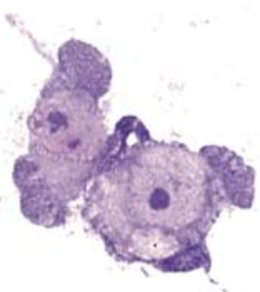

D

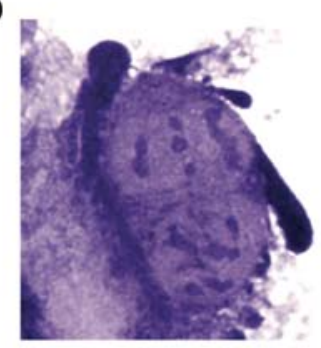

F

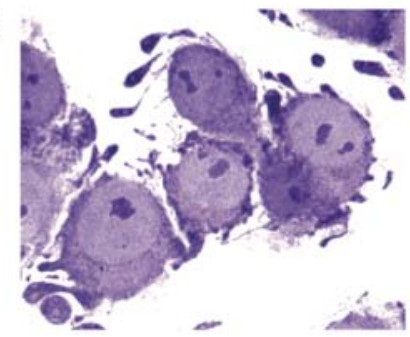

Figure 3. Cytospin preparation of adherent AGS cancer cells showing signs of apoptosis post-treatment with PFT. Monolayer AGS cells grown on cover glass were cultured with PFT $(5.0 \mathrm{mg} / \mathrm{ml})$ for $24 \mathrm{~h}$ and stained with Giemsa; magnification, $x 1,000$. Preparation shows: (A) non-apoptotic adherent cells; and (B-F) apoptotic adherent cells with chromatin condensation (B), membrane blebbing $(\mathrm{C})$, nuclear fragmentation and migration (D), encasement of fragments in membrane vesicles (E), and subsequent vesicle detachment from the cell $(\mathrm{F})$.

membrane blebbing in 4T1 cancer cells post-treatment with PFT (Fig. 4).

ii) Percentage of monolayer apoptotic AGS cells. The percentage of adherent AGS cells having morphological characteristics of apoptosis was examined at 0.5 and $24 \mathrm{~h}$ post-culture of cancer cells with PFT. Fig. 5 shows that a significant percentage of apoptosis was detected as early as $0.5 \mathrm{~h}$ post-culture of PFT with AGS cells $(\mathrm{p}<0.01)$. The apoptotic effect of PFT was further increased and became highly significant at $24 \mathrm{~h}(\mathrm{p}<0.001)$. The percent of apoptotic cancer cells post-treatment with PFT for $24 \mathrm{~h}$ was 2.4 -fold of those treated at $0.5 \mathrm{~h}$.

\section{Mechanisms underlying the PFT effect}

a) Mitochondrial membrane potential (MMP). The effect of PFT $(2.5 \mathrm{mg} / \mathrm{ml})$ on the MMP of AGS and 4T1 cells was examined by flow cytometry. Data in Fig. 6 show that treatment of AGS cancer cells with PFT for 3 days resulted in a significant decrease in mitochondrial potential as compared with control untreated cells $(\mathrm{p}=0.007)$. Fig. $6 \mathrm{~A}$ shows a representative flow histogram and Fig. 6B shows a bar graph representing the mean \pm SD of 3 different experiments. In contrast, data in Fig. 7 show that PFT had no effect on MMP of $4 \mathrm{~T} 1$ cells.
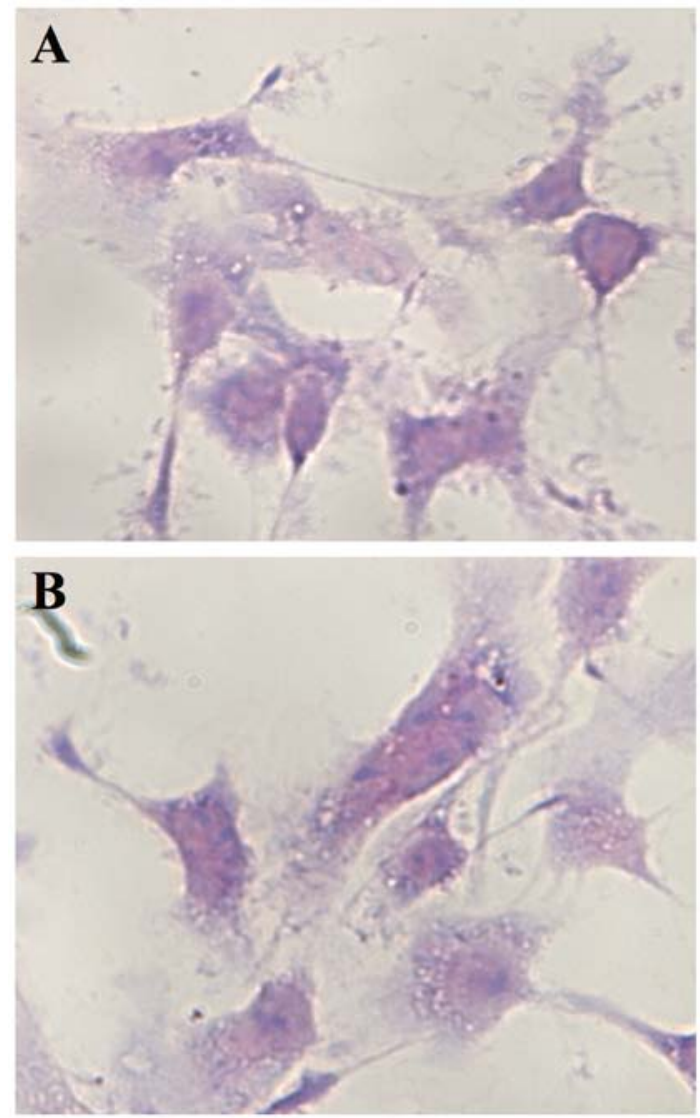

Figure 4. Cytospin preparation of adherent $4 \mathrm{~T} 1$ cancer cells post-treatment with PFT. Monolayer 4T1 cells grown on cover glass were cultured with PFT $(5.0 \mathrm{mg} / \mathrm{ml})$ for $24 \mathrm{~h}$ and stained with Giemsa; magnification, $\mathrm{x} 1,000$. Preparation shows: (A) control untreated adherent 4T1 cells; and (B) PFTtreated adherent $4 \mathrm{~T} 1$ cells. Note the absence of chromatin condensation and membrane blebbing.

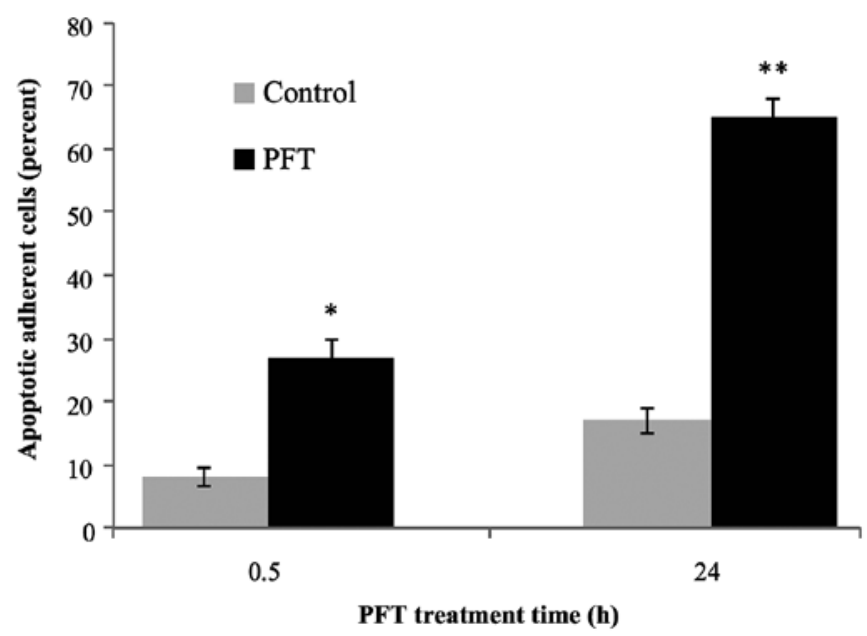

Figure 5. Percent of apoptotic adherent AGS cells at 0.5 and $24 \mathrm{~h}$. Tumor cells were cultured in the absence (grey) or presence of PFT (black). The percentage of adherent apoptotic tumor cells was determined using cytospin preparations. Data represent the mean \pm SD of 3 experiments. ${ }^{*} p<0.01$ and *** $\mathrm{p}<0.001$ as compared to control untreated cells.

b) Bcl2 expression. Bcl 2 expression of AGS cells post- culture with PFT $(2.5 \mathrm{mg} / \mathrm{ml})$ for 3 days was examined. Flow cytometry studies show that treatment with PFT resulted in a 

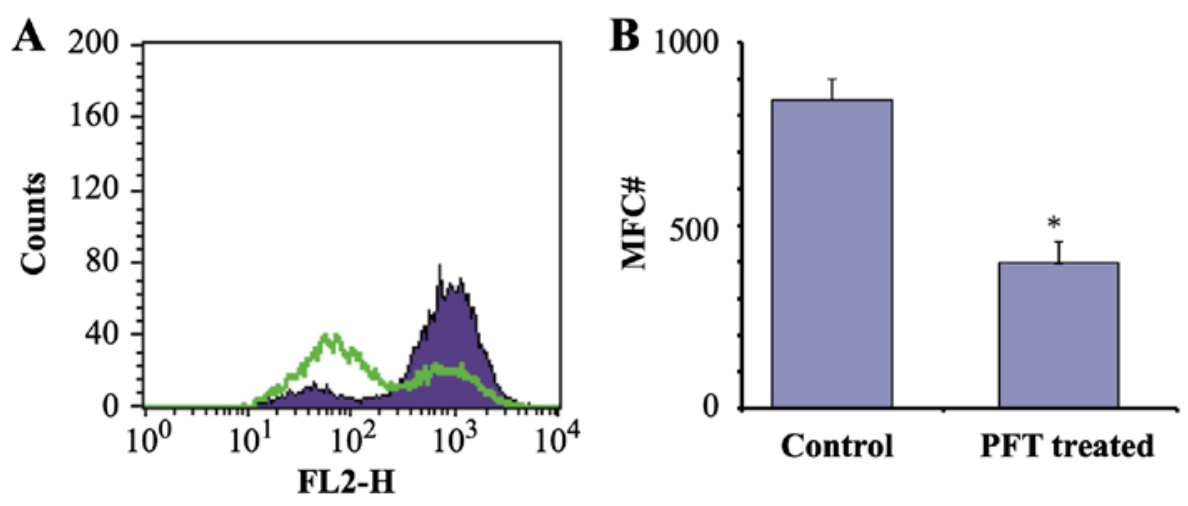

Figure 6. Effect of PFT on mitochondrial membrane potential (MMP) of AGS cells. AGS cancer cells (1x10 $)$ were cultured with PFT at a concentration of $2.5 \mathrm{mg} / \mathrm{ml}$ for 3 days and the MMP was detected by TMRE staining and flow cytometry. (A) A decrease in FL2 indicates depolarization (purple, control; green, PFT-treated). (B) Note that there was a significant change in mean fluorescence channel (MFC) number indicating PFT induced loss of membrane potential in AGS cancer cells $\left({ }^{*} \mathrm{p}=0.007\right)$.
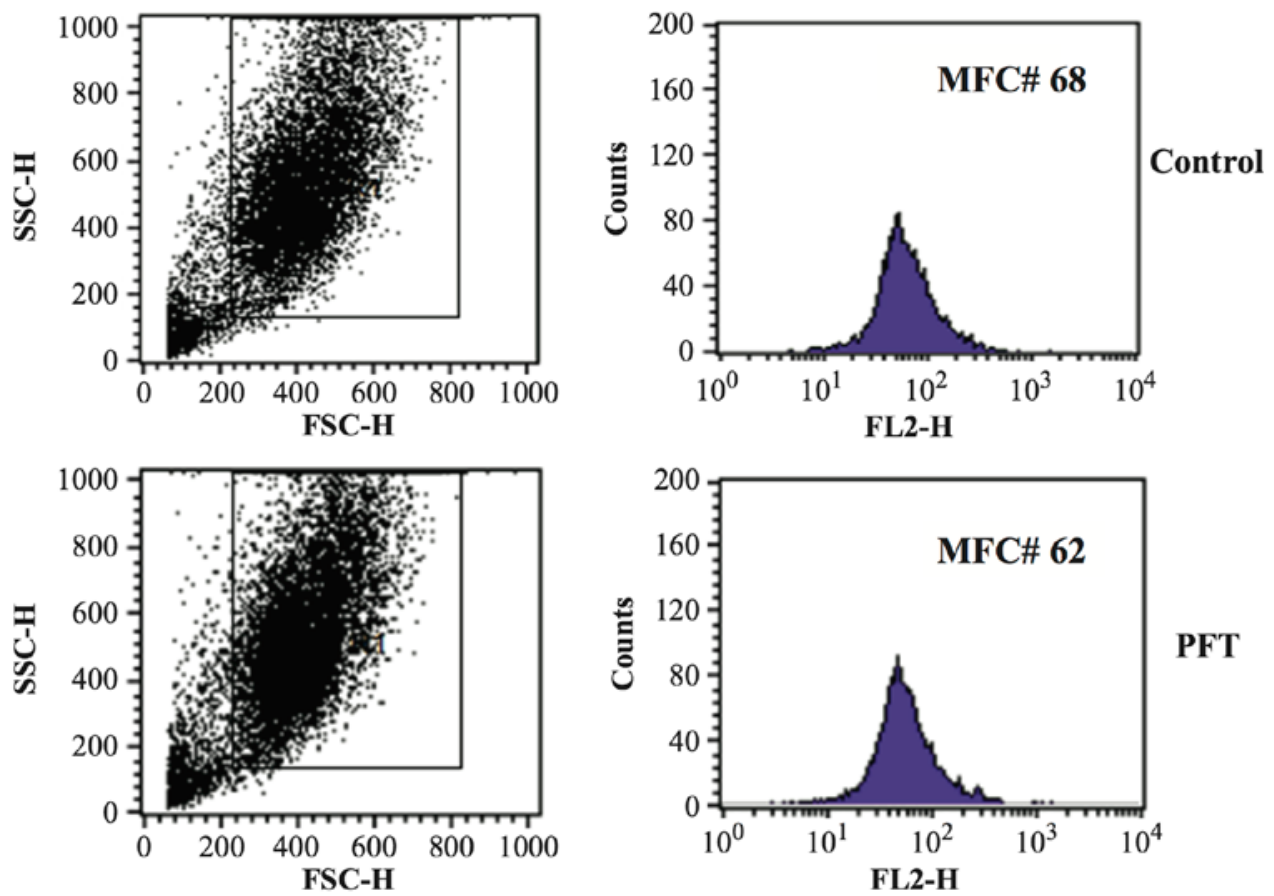

Figure 7. Effect of PFT on mitochondrial membrane potential (MMP) of $4 \mathrm{~T} 1$ cells. $4 \mathrm{~T} 1$ cancer cells $\left(1 \times 10^{5}\right)$ were cultured with PFT at a concentration of $2.5 \mathrm{mg} / \mathrm{ml}$ for 3 days and the MMP was detected by TMRE staining and flow cytometry. A decrease in FL2 indicates depolarization. Note that there was no significant change in mean fluorescence channel number indicating PFT had no effect on 4T1 membrane potential.

significant downregulation of the expression of Bcl2 of AGS cells $(\mathrm{p}=0.004)$ as compared to control untreated cancer cells. Fig. 8A shows a representative flow histogram and Fig. 8B shows a bar graph representing the mean \pm SD of 3 different experiments.

Effect of PFT on human PBMC. The effect of PFT treatment on PBMCs with respect to changes on the percentage of apoptotic cells was examined. PBMCs were co-cultured with PFT $(5.0 \mathrm{mg} / \mathrm{ml})$ for 3 days and the percentage of apoptotic cells was examined by flow cytometry. Fig. 9 shows that treatment of PBMCs with PFT caused no significant change in the percentages of apoptotic PBMCs as compared with control untreated cells.

\section{Discussion}

Lactic acid bacteria (LAB) has been found in milk products for thousands of years and is associated with inhibiting the growth of spoilage agents. Recently, scientists have revealed the additional potential of these bacteria as anticancer agents. Several reports suggest that fermented milk products and/or the fermentative bacteria themselves may have chemoprotective effects against cancer without the toxic side effects of conventional therapeutic drugs. In the present study we used a novel kefir product, Probiotics Fermentation Technology PFT, in which Lactobacillus kefiri P-IF is the main constituent. There are several characteristics that may allow P-IF to act as a potent anticancer agent. These include the ability of 

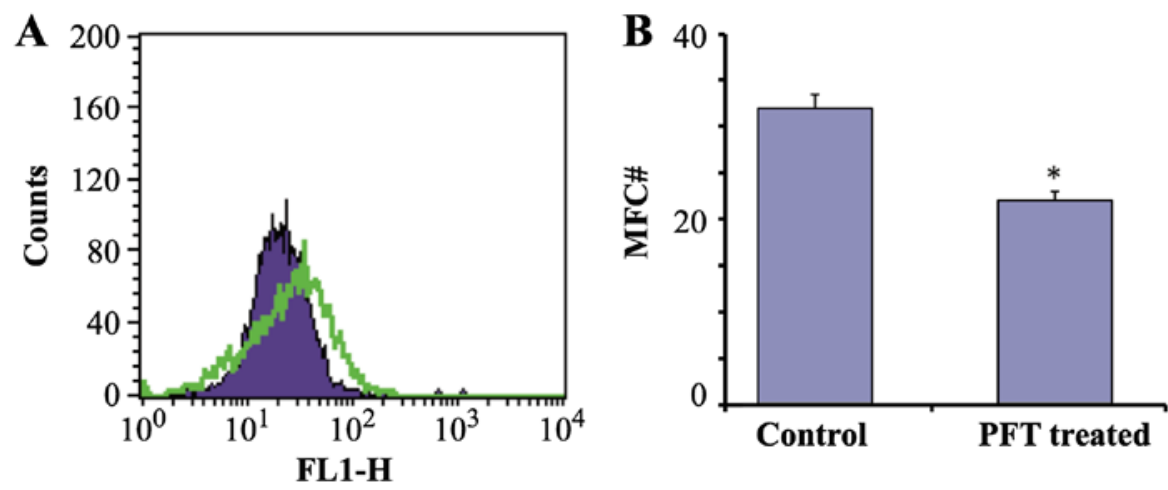

Figure 8. Effect of PFT on Bcl2 expression. AGS cells $\left(1 \times 10^{5}\right)$ were cultured with PFT at a concentration of $2.5 \mathrm{mg} / \mathrm{ml}$ for 3 days. Cells were then stained with FITC-labeled anti-Bcl 2 or isotype control, washed and analyzed by FACSCalibur. The percentage of cells expressing Bcl 2 and mean fluorescent intensity was determined ( $\mathrm{p}=0.004$; green, control; purple, PFT-treated).
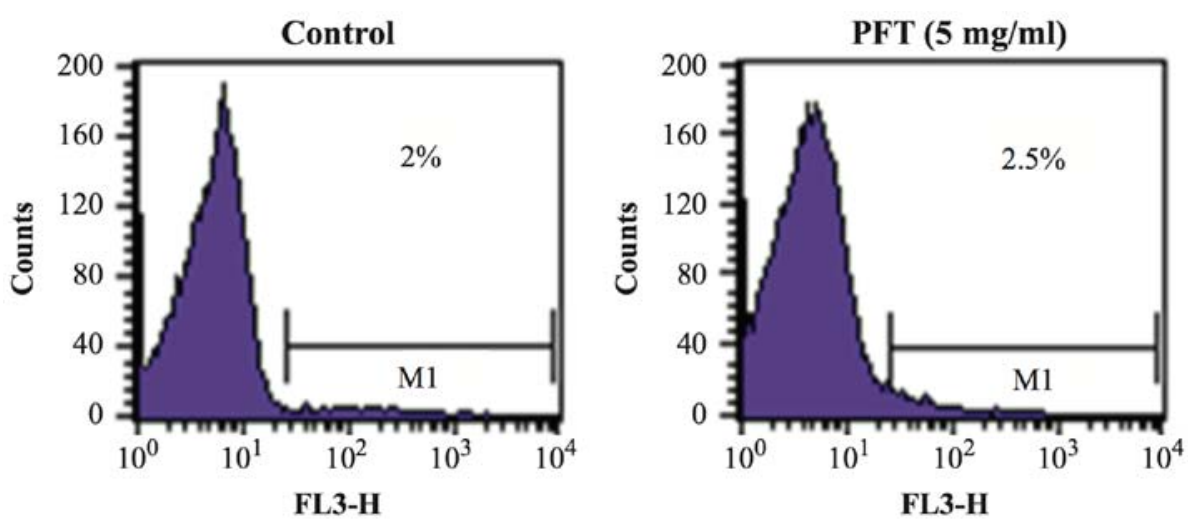

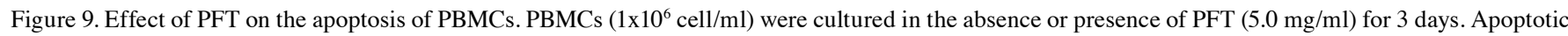
cells were determined by PI technique using FACSCalibur flow cytometer.

P-IF to grow three-dimensionally due to carbohydrate chains found on its surface, while other L. kefiri strains grow in a lengthwise-dimensional pattern. Moreover, P-IF can utilize galactose as a carbon source and produce carbonic acid (19). Our recent study demonstrated that PFT induces apoptosis on human multidrug-resistant (MDR) myeloid leukemia (HL60/AR) cells (16). These results prompted us to examine the apoptotic effect of PFT on other types of cancer. Data revealed that PFT exerts a selective apoptotic effect on human AGS cancer cells and did not exhibit apoptotic effects on 4T1 cells.

LAB can induce cancer cell death through a mechanism that involves apoptosis. There are two major pathways of apoptosis that have been extensively described in the literature; these are the extrinsic and intrinsic pathways. The former is mediated by activation of death receptors and caspase 8 , while the latter involves mitochondria and caspase 9 (20). The Bcl-2 family of proteins have been shown to play an important role in the mitochondrial pathway and in the maintenance of the MMP. In this study, treatment with PFT caused significant downregulation in the level of Bcl-2 of AGS cancer cells, this was associated with a decrease in the mitochondrial polarization of AGS cells. This may result in the release of pro-apoptotic molecules that cause the activation of caspases and eventually lead to apoptosis. Similar effects were noted on HL60/AR cells post-treatment with PFT (16).
Chemotherapy such as 5-fluorouracil (5-FU), cisplatin, and doxorubicin, which are often used for the treatment of gastric cancer, aim to initiate apoptosis in gastric cancer cells $(6,7)$. The apoptotic effect of PFT was shown to be both doseand time-dependent on AGS cells. Flow cytometry studies showed that PFT induces apoptosis which was detected at a concentration of $0.3 \mathrm{mg} / \mathrm{ml}$ and peaked at $66.3 \%$ at $5.0 \mathrm{mg} / \mathrm{ml}$. Morphological examination of Giemsa stained cytospin preparation confirmed the apoptotic effect of PFT against AGS cells, where the characteristics of apoptotic cells such as cell swelling, membrane blebbing and chromatin condensation were clearly identified. Induction of apoptosis by PFT was detected at $0.5 \mathrm{~h}$ post-treatment and the percentage of apoptotic cells showed a 2-fold increase at $24 \mathrm{~h}$. Earlier reports showed that other LAB agents such as L.lac CF induced DNA fragmentation and chromatin condensation against human stomach adenocarcinoma, SNU-1 (21).

The mitochondrial pathway appears to be the main route for the induction of apoptosis against gastric cancer cells by different types of probiotics such as $P$. freudenreichii (22), L. paracasei IMPC2.1, and L. rhamnosus GG (L.GG) (23). Similarly, induction of apoptosis via the mitochondrial pathway was also noted in colon cancer cells treated with probiotics including propionibacteria $(24,25)$, L. rhamnosus, Bifidobacterium latis (26), and L. delbrueckii (27). Furthermore, LAB induces the mitochondrial pathway 
of apoptosis in myeloid leukemia as well. For example, PFT induces apoptosis on human MDR myeloid leukemia (HL60/AR) (16), as well as L. reuteri (14) and L. casei rhamnosus (13) on human monocytic leukemia-derived cells.

Two alternative mechanisms can be proposed to account for the induction of apoptosis by LAB. First of all it is possible that LAB induces apoptosis by binding to Toll like receptors (TLR) on cancer cells and triggers apoptosis. This hypothesis is based on the reports that show some but not all TLRs trigger apoptosis in cancer cells (28-30). Second, it is possible that phagocytosed LAB may induce apoptosis. This hypothesis is based on studies by us and others that show cancer cells phagocytose microoraganism (31-33) and subsequently cancer cells undergo apoptosis $(17,34,35)$. The above hypotheses are not mutually exclusive. The reason for the inability of PFT to induce apoptosis in 4T1 may be due to the lack of appropriate TLRs that bind to PFT or failure of 4T1 cells to induce apoptosis post-phagocytosis of PFT.

Several studies have shown PFT to be a non-toxic agent. In this study, we noted no significant change in the percentage of apoptotic human PBMCs that were treated with PFT $(5.0 \mathrm{mg} /$ $\mathrm{ml}$ ) for 3 days. Additionally, in vivo studies have shown that PFT-treated mice had no change in body weight, and showed no macroscopic or histopathological abnormalities in different organs (36). These results suggest that PFT is a selective apoptotic inducer for gastric cancer, and is also a safe, non-toxic, potential therapy for the treatment of gastric cancer.

\section{Acknowledgements}

The authors would like to thank Paitos Co., Ltd., Yokohama, Kanagawa, Japan; grant no. T0099108. We would also like to thank our colleague and our collaborator Dr S. Gollapudi, UC Irvine, for his critical insight and guidance for this study. We would also like to thank our collaborator D. Pan, who is partially supported by NIH-NIMHD grant U54MD007598 (formerly U54RR026138) and NIH/NIMHD grant S21 MD000103 (CDU Life Sciences Institute). Partial support has also been provided by AXIS 5U54MD007598-06. Finally, we greatly appreciate the help of Dr Ben Winjum for help in preparing the figures and manuscript.

\section{References}

1. World Health Organization: The global and regional burden of cancer. In: World Cancer Report 2014. Stewart BW and Wild CP (eds). IARC Nonserial Publication, 2014.

2. National Cancer Institute (NCI): Stomach (gastric) cancer. http:// www.cancer.gov/types/stomach. Accessed July 1, 2014.

3. National Cancer Institute (NCI): SEER Stat Fact Sheets: Stomach Cancer. http://seer.cancer.gov/statfacts/html/stomach. $\mathrm{html}$. Accessed June 18, 2014.

4. World Health Organization: Stomach cancer. Gastric cancer prevention. In: World Cancer Report 2014. Stewart BW and Wild CP (eds). IARC Nonserial Publication, 2014.

5. National Cancer Institute (NCI): Gastric Cancer Treatment $\left(\mathrm{PDQ}^{\circledR}\right)$. http://www.cancer.gov/types/stomach/patient/stomachtreatment-pdq\#section/all NCI. Accessed July 1, 2014.

6. Sugamura K, Makino M, Shirai H, Kimura O, Maeta M, Itoh H and Kaibara N: Enhanced induction of apoptosis of human gastric carcinoma cells after preoperative treatment with 5-fluorouracil. Cancer 79: 12-17, 1997.

7. Matsuhashi N, Saio M, Matsuo A, Sugiyama Y and Saji S: The evaluation of gastric cancer sensitivity to 5-FU/CDDP in terms of induction of apoptosis: Time- and p53 expression-dependency of anticancer drugs. Oncol Rep 14: 609-615, 2005.
8. Singh J, Rivenson A, Tomita M, Shimamura S, Ishibashi N and Reddy BS: Bifidobacterium longum, a lactic acid-producing intestinal bacterium inhibits colon cancer and modulates the intermediate biomarkers of colon carcinogenesis. Carcinogenesis 18: 833-841, 1997.

9. Reddy BS and Rivenson A: Inhibitory effect of Bifidobacterium longum on colon, mammary, and liver carcinogenesis induced by 2 -amino-3-methylimidazo[4,5-f]quinoline, a food mutagen. Cancer Res 53: 3914-3918, 1993.

10. Fukui M, Fujino T, Tsutsui K, Maruyama T, Yoshimura H, Shinohara T, Fukui $\mathrm{M}$ and Nada O: The tumor-preventing effect of a mixture of several lactic acid bacteria on 1,2-dimethylhydrazine-induced colon carcinogenesis in mice. Oncol Rep 8: 1073-1078, 2001

11. Abd el-Gawad IA, el-Sayed EM, Hafez SA, el-Zeini HM and Saleh FA: Inhibitory effect of yoghurt and soya yoghurt containing bifidobacteria on the proliferation of Ehrlich ascites tumour cells in vitro and in vivo in a mouse tumour model. Br J Nutr 92: 81-86, 2004.

12. Kim JY, Woo HJ, Kim YS, Kim KH and Lee HJ: Cell cycle dysregulation induced by cytoplasm of Lactococcus lactis ssp lactis in SNUC2A, a colon cancer cell line. Nutr Cancer 46: 197-201, 2003.

13. Chiu YH, Hsieh YJ, Liao KW and Peng KC: Preferential promotion of apoptosis of monocytes by Lactobacillus casei rhamnosus soluble factors. Clin Nutr 29: 131-140, 2010.

14. Iyer C, Kosters A, Sethi G, Kunnumakkara AB, Aggarwal BB and Versalovic J: Probiotic Lactobacillus reuteri promotes TNF-induced apoptosis in human myeloid leukemia-derived cells by modulation of NF-kappaB and MAPK signalling. Cell Microbiol 10: 1442-1452, 2008.

15. McIntosh GH and Le Leu RK: The influence of dietary proteins on colon cancer risk. Nutr Res 21: 1053-1066, 2001.

16. Ghoneum M and Gimzewski J: Apoptotic effect of a novel kefir product, PFT, on multidrug-resistant myeloid leukemia cells via a hole-piercing mechanism. Int J Oncol 44: 830-837, 2014.

17. Ghoneum $\mathrm{M}$ and Gollapudi S: Induction of apoptosis in breast cancer cells by Saccharomyces cerevisiae, the baker's yeast, in vitro. Anticancer Res 24: 1455-1463, 2004.

18. Ghoneum M and Gollapudi S: Modified arabinoxylan rice bran (MGN-3/Biobran) enhances yeast-induced apoptosis in human breast cancer cells in vitro. Anticancer Res 25A: 859-870, 2005.

19. Suzuki K, Tani H, Yabumoto T, Yabumoto $Y$ and Yoshida Y: Novel fermented milk product and use thereof. US Patent No. US 20110123640 A1. Filed Jun 8, 2009; issued May 26, 2011.

20. Elmore S: Apoptosis: A review of programmed cell death. Toxicol Pathol 35: 495-516, 2007.

21. Kim SY, Lee KW, Kim JY and Lee HJ: Cytoplasmic fraction of Lactococcus lactis ssp. lactis induces apoptosis in SNU-1 stomach adenocarcinoma cells. Biofactors 22: 119-122, 2004.

22. Cousin FJ, Jouan-Lanhouet S, Dimanche-Boitrel MT, Corcos L and Jan G: Milk fermented by Propionibacterium freudenreichii induces apoptosis of HGT-1 human gastric cancer cells. PLoS One 7: e31892, 2012.

23. Orlando A, Refolo MG, Messa C, Amati L, Lavermicocca P, Guerra V and Russo F: Antiproliferative and proapoptotic effects of viable or heat-killed Lactobacillus paracasei IMPC2.1 and Lactobacillus rhamnosus GG in HGC-27 gastric and DLD-1 colon cell lines. Nutr Cancer 64: 1103-1111, 2012.

24. Jan G, Belzacq AS, Haouzi D, Rouault A, Métivier D, Kroemer G and Brenner C: Propionibacteria induce apoptosis of colorectal carcinoma cells via short-chain fatty acids acting on mitochondria. Cell Death Differ 9: 179-188, 2002.

25. Lan A, Lagadic-Gossmann D, Lemaire C, Brenner C and Jan G: Acidic extracellular $\mathrm{pH}$ shifts colorectal cancer cell death from apoptosis to necrosis upon exposure to propionate and acetate, major end-products of the human probiotic propionibacteria. Apoptosis 12: 573-591, 2007.

26. Altonsy MO, Andrews SC and Tuohy KM: Differential induction of apoptosis in human colonic carcinoma cells (Caco-2) by Atopobium, and commensal, probiotic and enteropathogenic bacteria: Mediation by the mitochondrial pathway. Int J Food Microbiol 137: 190-203, 2010.

27. Wan Y, Xin Y, Zhang C, Wu D, Ding D, Tang L, Owusu L, Bai $\mathrm{J}$ and $\mathrm{Li}$ W: Fermentation supernatants of Lactobacillus delbrueckii inhibit growth of human colon cancer cells and induce apoptosis through a caspase 3-dependent pathway. Oncol Lett 7: 1738-1742, 2014. 
28. Fukata M, Shang L, Santaolalla R, Sotolongo J, Pastorini C, España C, Ungaro R, Harpaz N, Cooper HS, Elson G, et al: Constitutive activation of epithelial TLR4 augments inflammatory responses to mucosal injury and drives colitis-associated tumorigenesis. Inflamm Bowel Dis 17: 1464-1473, 2011.

29. Fúri I, Sipos F, Germann TM, Kalmár A, Tulassay Z, Molnár B and Múzes G: Epithelial toll-like receptor 9 signaling in colorectal inflammation and cancer: Clinico-pathogenic aspects. World J Gastroenterol 19: 4119-4126, 2013.

30. Li TT, Ogino S and Qian ZR: Toll-like receptor signaling in colorectal cancer: Carcinogenesis to cancer therapy. World J Gastroenterol 20: 17699-17708, 2014.

31. Vandenberghe J, Verheyen A, Lauwers S and Geboes K: Spontaneous adenocarcinoma of the ascending colon in Wistar rats: The intracytoplasmic presence of a Campylobacter-like bacterium. J Comp Pathol 95: 45-55, 1985.

32. Ghoneum M and Gollapudi S: Apoptosis of breast cancer MCF-7 cells in vitro is induced specifically by yeast and not by fungal mycelia. Anticancer Res 26: 2013-2022, 2006.
33. Ghoneum M, Grewal I, Brown J, Osborne R, Elembabi H and Gill G: Phagocytosis of candida albicans by lymphatic tumour cells in vitro. Acta Histochem 105: 127-133, 2003.

34. Ghoneum M, Hamilton J, Brown J and Gollapudi S: Human squamous cell carcinoma of the tongue and colon undergoes apoptosis upon phagocytosis of Saccharomyces cerevisiae, the baker's yeast, in vitro. Anticancer Res 25A: 981-989, 2005.

35. Ghoneum M, Matsuura M, Braga M and Gollapudi S: S. cerevisiae induces apoptosis in human metastatic breast cancer cells by altering intracellular $\mathrm{Ca}^{2+}$ and the ratio of $\mathrm{Bax}$ and $\mathrm{Bcl}-2$. Int $\mathrm{J}$ Oncol 33: 533-539, 2008

36. Paitos Co: Ltd. Yokohama, Kanagawa, Japan: Increase the good bacteria held by nature, ideal AH21 is a functional food, consider preventive medicine and food. http://www.bio-j.net/ken00.html. Accessed June 14, 2013 